\title{
Balkanologie
}

Balkanologie Revue d'études pluridisciplinaires

Vol. XII, $n^{\circ} 1$ | 2010

Volume XII Numéro 1

\section{Pavlowitch (Stevan K.), Hitler's new disorder, the Second World War in Yugoslavia}

London: Hurst and company, 2008, xix + 333 pages

Joseph Krulic

\section{CpenEdition}

\section{Journals}

Édition électronique

URL : http://journals.openedition.org/balkanologie/2156

DOI : 10.4000/balkanologie.2156

ISSN : 1965-0582

Éditeur

Association française d'études sur les Balkans (Afebalk)

Référence électronique

Joseph Krulic, "Pavlowitch (Stevan K.), Hitler's new disorder, the Second World War in Yugoslavia »,

Balkanologie [En ligne], Vol. XII, n 1 | 2010, mis en ligne le 02 avril 2010, consulté le 17 décembre 2020

URL : http://journals.openedition.org/balkanologie/2156; DOI : https://doi.org/10.4000/balkanologie. 2156

Ce document a été généré automatiquement le 17 décembre 2020.

(c) Tous droits réservés 


\section{Pavlowitch (Stevan K.), Hitler's new disorder, the Second World War in Yugoslavia}

London: Hurst and company, 2008, xix +333 pages

Joseph Krulic

\section{RÉFÉRENCE}

Stevan K. Pavlowitch, Hitler's new disorder, the Second World War in Yugoslavia, London:

Hurst and company, 2008, xix + 333 p.

1 Le nouvel ouvrage de Stevan K Pavlović constitue un bilan de l'état des connaissances en 2008 sur une question cruciale par ses enjeux historiographies et politiques. L'auteur le signale dans une préface raisonnée, où il rappelle que la « seconde destruction de la Yougoslavie, par les Yougoslaves ", dans les années 1990, a estompé l'intérêt du public, même cultivé, pour la première destruction par Hitler et Mussolini. Beaucoup de sources sont désormais accessibles, et des comparaisons sont possibles. L'histoire officielle de l'époque titiste, qui attribuait au "mouvement de libération nationale" animé par le parti communiste un rôle glorieux dans une coalition antifasciste, où les adversaires du parti communiste étaient simplement des "collaborateurs", et où aucune guerre civile n'était supposée s'être déroulée, se trouve dévaluée dans sa version aussi bien simpliste que sophistiquée, cette dernière ayant été répandue par des acteurs britanniques comme Deakin - envoyé de Churchill auprès de Tito en 1943 - en suggérant que Churchill avait donné son appui de façon rationnelle au camp le plus efficace pour unifier la Yougoslavie dans le guerre et combattre les Allemands.

2 Du point de vue méthodologique, cette période, comme toute l'histoire yougoslave, illustre un problème général de la recherche historique : l'appréciation des statistiques. Comme le dit l'auteur, "les documents yougoslaves utilisent les chiffres comme les chroniqueurs médiévaux ou les prophètes de l'Ancien testament ». Le chiffre officiel de 
la Yougoslavie titiste était de 1706 million de morts, mais les calculs de Bogoljub Kočović ont permis d'établir un chiffre moyen de 1014 million, compris entre un minimum de 0,9 million et un maximum de 1150 million, en se fondant sur les recensements et la démographie réelle des populations, en 1939 et en 1945. Stevan Pavlović est d'une prudence extrême dans toutes les évaluations et n'hésite à dire que le chiffre ne peut, à l'heure actuelle, être connu, comme dans le cas des massacres de mai 1945, où Žerjavić, l'autre grand statisticien démographe de la guerre, estime que 60000 Croates ont été tués (p. 262), chiffre qui s'ajouterait, dans cette hypothèse, à 24000 Slovènes (ibid., toujours selon Žerjavić).

3 Stevan Pavlović excelle dans l'analyse de la multiplicité des acteurs et de leurs ambiguïtés. Il en est ainsi des multiples groupes de "Tchetniks", terme générique qui désigne des acteurs relativement différents dans leurs objectifs, leurs méthodes et leurs parcours, même s'ils ont partagé une commune identité serbe. On savait depuis longtemps que ces groupes n'étaient pas disciplinés, ni unis sous un commandement commun, qui aurait pu être celui de Mihajlović (que le gouvernement royal avait nommé ministre et général, ce qui lui conférait une autorité légale). Mais l'ouvrage va plus loin dans l'analyse des compromissions de ces groupes avec les Italiens, et, plus rarement, les Allemands. Il montre aussi (pp. 152-153) l'ambivalence de ces relations : des groupes que les Alliés considéraient comme des résistants - en tout cas jusqu'en 1943 - étaient en fait armés par les Italiens; les évolutions de ces groupes provoquaient les Allemands, désireux de détruire ces "bandes" virtuellement hostiles. Les Italiens eux-mêmes divisaient les Tchetniks entre les "Nostri », ceux de Mihajlović, hostiles, et un groupe d'hésitants.

4 Ces comportements ambivalents s'expliquaient, en partie, par une situation de frustration ou d'impuissance chez la plupart des acteurs. Les Allemands et les Italiens avaient peu de troupes disponibles, les Alliés avaient peu d'armes à offrir avant 1944, le débarquement allié attendu n'a jamais eu lieu, les Partisans étaient moins nombreux que ce qu'en estimèrent les Italiens en 1942, etc.

5 L'auteur revient notamment sur les «négociations de mars »: en mars 1943, en pleine "bataille de la Neretva" (opération Weiss), Tito a envoyé trois de ses collaborateurs (dont Milovan Djilas) à Zagreb pour négocier avec le haut commandement allemand une trêve, qui a été effective pendant six semaines. L'objet initial de la négociation était un échange de prisonniers, mais les émissaires ont déclaré que si les Britanniques débarquaient en Yougoslavie sans l'autorisation des Partisans, ceux-ci les combattraient. Cette affaire est bien connue depuis 1977 grâce à la publication du livre de Djilas Wartime ${ }^{1}$, mais les premiers documents allemands publiés datent de 1950 et la dernière version des mémoires de Vladimir Velebit, l'un des trois négociateurs titistes (citée dans l'ouvrage), est de 2002.

6 Les analyses de Stevan Pavlovic sur les contradictions de l'État oustachi de Pavelić sont très précises et nuancées, notamment lorsqu'il en analyse les relations avec l'Italie. Privé d'une partie de la Dalmatie par l'Italie, cet État, où les Oustachis n'étaient en 1941 que 900 avec, selon Pavlović, 40000 sympathisants avérés, n’a jamais réellement pu prendre possession de son territoire. Partagé entre une zone militaire allemande et une zone italienne symétrique, ravagée par une hyperinflation chronique, phénomène rarement signalé et qui constitue un apport important de l'ouvrage de Pavlović, cet État, en tout cas jusqu'au printemps de 1944, pouvait sembler être une approximation de l'état de nature chaotique selon Hobbes, dont les massacres de Serbes de Croatie, 
surtout en 1941, phénomène souvent analysé et mieux connu, constituent la sinistre illustration. Cependant, Stevan Pavlović note que l'idée d'indépendance de la Croatie était populaire, notamment à Zagreb et en milieu urbain - du moins en 1941 ; et qu'en 1945, l'armée croate des Domobrani était plus nombreuse et plus efficiente qu'on ne le croit généralement. L'intérêt et le sérieux de l'ouvrage se vérifient dans ce type de nuances.

7 Stevan Pavlovic a entrepris des recherches de longue haleine sur les formes de domination ou d'influence de l'Italie fasciste sur les rives de l'Adriatique. Sur ce point précis, on notera cependant que s'il fait une part substantielle aux formes de répression - notamment en 1942 sous les ordres du général Robotti en Slovénie (partie sud) et dans la partie de la Croatie qu'ils occupaient (Dalmatie, Gorski Kotar) - il ne s'attarde néanmoins pas beaucoup sur les aspects “concentrationnaires" de cette politique. S'il note que des "Partisans" sont envoyés dans des «camps de concentration » (p. 145), la seule mention de l'île de Rab (p. 71) se réfère à un épisode de février 1943 où les Italiens ont protégé des juifs dans ce lieu; il semble ignorer le fait, obsédant dans la mémoire croate et slovène, que l'île fut, pendant l'année 1942 et jusqu'en janvier 1943, un camp de concentration d'où l'espoir de sortir vivant était faible, si l'on consulte la liste des victimes (notre grand père maternel y est mort en décembre $1942^{2}$ ).

Cela montre une des difficultés de ce type de synthèse : l'analyse des différents théâtres d'opérations et de conjonctures politiques relativement disparates, malgré les liens existant entre toutes ses évolutions. L'auteur se fait une règle de ne parler des évolutions internationales que dans la mesure où cela interfère avec le théâtre yougoslave ou dans la mesure où les acteurs locaux règlent leurs comportements suivant la perception qu'ils ont de l'évolution globale. Il s'efforce, généralement avec succès, de démêler l'entrelacement des multiples évolutions locales et globales, variant l'échelle des analyses. Dans cet ouvrage, la Seconde Guerre mondiale dans l'espace yougoslave s'apparente plus à un drame shakespearien, plein de bruit et de fureurs, qu'à la marche triomphale d'une idée, communiste, nationale ou autre. On s'en doutait, mais le livre de Stevan Pavlović en apporte la précise et précieuse confirmation.

\section{NOTES}

1. Djilas (Milovan), La Guerre dans la Guerre, Paris : Robert Laffont, 1980 (éd. française).

2. Voir par exemple, sur le camp de Rab, le site http://www.criminidiguerra.it/DecArbe.shtml 